\title{
O conhecimento e sua influência na escolha pelo trabalho coletivo: estudo de caso na Rede de Catadores de Resíduos Sólidos Recicláveis do Estado do Ceará
}

\author{
Roberto Tadeu Ramos Morais \\ Programa de Pós-Graduação Mestrado em Desenvolvimento Regional das Faculdades Integradas de Taquara \\ (Faccat) \\ Newton José Cavalcante Gonçalves \\ Especialista em Gestão de Cooperativas da Faculdade de Tecnologia do Cooperativismo (Escoop)
}

\section{Resumo}

Este trabalho apresenta um estudo analítico do conhecimento e sua influência na construção do trabalho coletivo na Rede de Catadores de Resíduos Sólidos Recicláveis do Estado do Ceará. As atividades desenvolvidas pelos catadores são importantes para o meio ambiente e para a sociedade, porém tais trabalhadores são discriminados e marginalizados pela sociedade. $O$ estudo tem por objetivo analisar se o nível de conhecimento formal do catador de material reciclável influencia na sua escolha pelo trabalho coletivo em uma rede de catadores. Com base nos principais teóricos da temática abordada, como Gonçalves (2005), Piaget (2007) e Quirino (2010), e na Lei 12.305/10, foram analisados os relacionamentos entre o conhecimento, a cooperação, a rede e os catadores de materiais. A metodologia utilizada fundamenta-se no enfoque sistêmico, aliado a uma pesquisa qualitativa em um estudo de caso. Os dados foram coletados junto aos gestores e aos catadores de material reciclável. A partir dos resultados foi possível perceber que a adesão ao trabalho coletivo não se relaciona com o conhecimento formal obtido pelos catadores de material reciclável, uma vez que os mesmos quase não possuem conhecimento escolarizado.

Palavras-chave | Catadores; Ceará; conhecimento; resíduos sólidos recicláveis; trabalho coletivo.

Código JEL | J21; QR3; R10. 


\title{
THE KNOWLEDGE AND ITS INFLUENCE ON CHOOSING THE COLLECTIVE WORK: A CASE STUDY THROUGH THE RECYCLABLE SOLID WASTE PICKERS' NETWORK IN THE STATE OF CEARÁ
}

\begin{abstract}
This material presents an analytical research about knowledge and its influence on the construction of collective work on the recyclable waste pickers' network of the Brazilian state, Ceará (CE). The activities developed by the waste "pickers" are important to the environment and society, but are discriminated and marginalized by society. This study aims to analyze if the formal knowledge level of the recyclable waste pickers influence in their choice for collective work on a pickers' network. Based on the main theoretical about the discussed theme, such as Gonçalves (2005), Piaget (2007), Quirino (2010) and the Law 12.305/2010, relationships were analyzed among knowledge, cooperation, the network and the "pickers". The methodology is based on the systematic approach combined with a qualitative research on a case study. The data was collected with the managers and the recyclable material pickers through semi structured interview. From the results it was revealed that the adherence to collective work is not related the formal knowledge obtained by waste pickers, since they have almost no schooled knowledge.
\end{abstract}

Keywords | Ceará, collective work; knowledge; pickers; recyclable solid waste.

JEL-Code | J21; QR3; R10.

\section{EL CONOCIMIENTO Y SU INFLUENCIA EN LA ELECCIÓN POR EL TRABAJO COLECTIVO: UN ESTUDIO DE CASO EN LA RED DE RECOLECTORES DE RESIDUOS SÓLIDOS RECICLABLES DEL ESTADO DE CEARÁ}

\section{Resumen}

Este artículo presenta un estudio analítico de los conocimientos y su influencia en la construcción del trabajo colectivo en la red de recolectores de residuos sólidos reciclables del Estado de Ceará. Las actividades desarrolladas por los recolectores son importantes para el medio ambiente y la sociedad. Sin embargo, estos trabajadores son discriminados y marginados. El estudio pretende examinar si el nivel de conocimiento formal del recolector de material reciclable influye en su elección por el trabajo colectivo en una red de recolectores. Sobre la base de los principales teóricos sobre el tema abordado (Gonçalves, 2005; Piaget, 2007; Quirino, 2010) y la Ley 12.305/10 se analizaron las relaciones entre el conocimiento, la cooperación, las redes y los recolectores de materiales reciclables. La metodología utilizada se basa en un enfoque sistémico combinado con una investigación cualitativa en un estudio de caso. Los datos se obtuvieron de los gestores y los recolectores de materiales reciclables mediante entrevistas semiestructuradas. A partir de los resultados fue posible darse cuenta de que la adhesión al trabajo colectivo no se relaciona con el conocimiento obtenido por los recolectores de material reciclable, ya que los mismos casi no tienen conocimiento escolarizado.

Palabras-clave | Ceará; conocimiento; recolectores; residuos sólidos reciclables; trabajo colectivo.

Código JEL | J21; QR3; R10. 


\section{Introdução}

De forma racional, pode-se entender que os catadores de material reciclável representam um segmento da população que se encontra à margem do que a sociedade propõe para a sustentabilidade dos direitos básicos de cidadania, dentre eles, empregos formalmente constituídos e que garantam sua sobrevivência. O segmento em questão sobrevive da venda do material reciclável dispensado pela sociedade, marcada pelo consumismo de bens e serviços, assim como pela competição desenfreada do ter em oposição ao ser.

Catar o lixo, além de materializar uma alternativa de renda para quem não possui emprego formal nem dispõe de qualificação adequada para assumir empregos ofertados pelo mercado de trabalho, pode ser entendido como um meio de contribuir positivamente para a preservação e sustentabilidade do meio ambiente. Portanto, a atividade se ampara em três dimensões: a) social - pela inclusão social dos catadores no mercado de trabalho, movimentando a indústria da reciclagem; b) econômica - gerando emprego e renda e, c) ambiental: preservação dos recursos naturais. No entanto, a preocupação reinante, por parte dos catadores, tem sido a luta pela sobrevivência, e, por parte dos compradores do material reciclável, tem sido o lucro, próprio de uma sociedade que se orienta pelo modo capitalista. Todavia, é possível afirmar que, perambulando pelas ruas, os catadores de material reciclável constroem suas histórias contra a precariedade econômica, selecionando as sobras dispersadas pela sociedade de consumo, as quais se tornam requisitos necessários para sua sobrevivência.

Nos últimos dez anos (2004-2014) surgiram pesquisas (MEDEIROS; MACEDO, 2006; ZANETTI; GENTIL; TORRES, 2006; SOTO, 2010) interessadas em desvendar tanto o universo das cooperativas e redes de catadores que se constituíram para coletar materiais recicláveis como também para observar as características sócio-demográficas desses trabalhadores. Contudo, ainda faltam estudos que analisem o impacto do conhecimento formal para a escolha pelo trabalho coletivo em rede de catadores de material reciclável.

O artigo está organizado em quatro seções. A primeira apresenta a ressignificação do lixo e procura caracterizar a ocupação do catador de material reciclável. A segunda seção discorre sobre o conhecimento, o trabalho coletivo e as redes de cooperação. A terceira apresenta os procedimentos metodológicos de levantamento e análise dos dados. A quarta seção apresenta os resultados da pesquisa com os catadores de materiais recicláveis e algumas observações baseadas em observações de campo. Por último, conclui-se que o conhecimento não influencia a escolha, por parte do catador de material reciclável, para atuar em trabalho coletivo na forma de rede. 


\section{Ressignificando o conceito do lixo e do catador de material reciclável}

O que é mesmo o lixo? A palavra tem origem no latim lix, que significa cinza. Antigamente, na Europa, boa parte dos resíduos vinha do fogão e da lareira, eram restos de lenha, carvão e cinzas. Já os restos dos alimentos eram utilizados para ração animal e esterco para horta e pomar.

O lixo é uma nomenclatura utilizada para denominar todos os materiais inúteis, descartáveis e que se jogam fora, geralmente em lugar público. Sua coleta é realizada pelo poder público instituído, ou, na inexistência desse serviço, são incinerados, enterrados ou, ainda, compõem o cenário dos grandes centros urbanos (GONÇALVES, 2005). Para o autor, o lixo, assim como as pessoas que dele cuidam, passa por um processo de exclusão social e vulnerabilidade, evidenciadas pelas marcas do preconceito a essa ocupação de trabalho, sendo a figura do catador associada ao próprio lixo.

A legislação brasileira estabelece que o lixo doméstico é atribuição da prefeitura municipal, cumprindo-lhe a missão de assegurar sua coleta e disposição final.

Calderoni (2003, p. 51) entende o "[...] lixo domiciliar como todo material sólido, ao qual seu proprietário ou possuidor não atribui mais valor e dele desejam descartar-se, atribuindo ao poder público a responsabilidade pela sua disposição final". Denota-se que o descaso dos órgãos públicos e da sociedade com a educação, saúde, moradia e outros setores é repetido com o lixo.

Porém, é necessário dar novo significado a esse conceito, deixando de enxergá-lo como uma coisa suja e inútil em sua totalidade. A maior parte dos materiais que vai para o lixo pode e deveria ser reciclada. Nesse sentido, Abreu (2001, p. 26) afirma:

[...] o lixo orgânico (sobras de comida) representa cerca de 65\% a 70\% do total do lixo produzido nos países chamados de Terceiro Mundo; o lixo rejeitado (de banheiros, pilhas, lâmpadas) perfaz apenas cerca de $5 \%$ da massa total dos resíduos, isto é, o lixo propriamente dito que não é passível de reciclagem, reuso ou compostagem; e os materiais recicláveis (plásticos, papéis, metais e vidros) que compõem aproximadamente $25 \%$ a $30 \%$ de peso total do lixo, representam a maior parcela em volume.

Pode-se observar pelos dados apresentados que o volume de lixo produzido pela sociedade é muito alto, o que pode levar a reflexão sobre como reutilizá-lo ou reciclá-lo, considerando a boa qualidade de vida dos que habitam o planeta Terra e a conservação de um meio ambiente saudável, que considere as gerações de hoje e as de amanhã. A produção de bens, através do reuso e da reciclagem, já 
demonstrou ser uma prática economicamente eficiente, tecnologicamente viável e ambientalmente correta. Apresenta-se como um potente instrumento de redução da pobreza e de inclusão social.

Vale aqui fazer uma diferenciação entre o conceito de reutilização e reciclagem do lixo. O primeiro consiste no aproveitamento de produtos sem que estes sofram quaisquer tipos de alterações ou processamentos complexos. O segundo, a reciclagem, consiste em aproveitar os resíduos para fabricar novos produtos, idênticos ou não ao que lhes deu origem (LOCATELLI, SANCHEZ e ALMEIDA, 2008).

A reciclagem pode ser do tipo artesanal ou industrial. Artesanal, quando se utilizam processos de transformação com baixa sofisticação, e industrial, quando esses processos são mecanizados e em condições de fabricar produto em larga escala. A reciclagem artesanal também pode ser vista como uma forma de reutilização, pois os resíduos passam por poucas modificações (QUIRINO et al., 2010).

Calderoni (2003) apresenta outras classificações para o lixo. A primeira ele denomina de lixo residencial, ou seja, aquele produzido todos os dias nas casas; é bem heterogêneo, sendo formado por papel, metais, plásticos, vidros e restos de alimentos. Esse lixo, na grande maioria das cidades brasileiras, tem como destino um aterro sanitário, para ser enterrado. Nesse aterro o lixo sofre uma decomposição lenta e anaeróbica, liberando gases como o metano. O gás metano, na maioria das vezes, não é aproveitado, mas pode ser recolhido e usado como combustível. A segunda classificação refere-se ao lixo hospitalar, isto é, aquele que resulta da manipulação em hospitais e clínicas. Este é formado, em sua maioria, por seringas, luvas, fraldas, sondas, cateteres e demais materiais descartáveis, que representam grande risco à saúde, uma vez que podem estar contaminados por micro-organismos causadores de doenças. Seu recolhimento é realizado por empresas especializadas, pois o seu destino é o incinerador, onde é queimado. A terceira classificação refere-se ao lixo industrial, que é aquele resultante dos processos de produção das indústrias, variando de acordo com o segmento. Assim, metalúrgicas, empresas alimentícias e químicas têm um lixo bem diferente, requerendo, cada qual, um tratamento especial.

A partir dessa classificação, é possível denotar os malefícios que a ocupação do catador de materiais recicláveis traz ao homem, em relação aos riscos e cuidados com a saúde, decorrentes da transmissão de doenças provocadas pelo manuseio do lixo e da precariedade de proteção em face de não utilização, muitas vezes, dos equipamentos de proteção individual.

A ocupação do catador de materiais recicláveis de resíduos sólidos não é nova no Brasil. O comércio de materiais refugados já era realizado no século XIX, decorrente da revolução industrial. Segundo Pinhel (2013), no início do século 
$\mathrm{XX}$, o papel já era reciclado, e também há registros de compradores de garrafas e materiais ferrosos em São Paulo, os quais eram conhecidos como garrafeiros.

Com o avanço tecnológico e industrial, ocorrido ao longo do século XX, houve uma mudança de perfil deste trabalhador, decorrente do crescimento das cidades, da explosão urbana e do consumismo exacerbado, que alteram significativamente o estilo de vida da sociedade, a quantidade de resíduos gerados (papel, sucatas e embalagem) e o aumento do nível de desemprego.

Nesse cenário, Pinhel (2013) relata que houve um incremento substancial da ação dos catadores nas ruas. Isso se confirma ao ser analisada a Pesquisa Nacional de Saneamento Básico (PNSB), que investiga as condições de saneamento básico de todos os municípios brasileiros. Em sua última edição, publicada em 2008, existem aproximadamente 70,5 mil catadores informais atuando em ruas e lixões, e 30,3 mil organizados em cooperativas ou associações. Esses números, que já devem ser maiores, retratam a dura realidade brasileira nas condições ambientais e suas implicações diretas na saúde pública e na qualidade de vida da população.

As primeiras iniciativas para organizar a categoria datam da década de 1990, com a formação do Movimento Nacional de Catadores de Materiais Recicláveis (MNCMR), surgido em 1999. Utilizando-se das informações de Abreu (2001), percebe-se que se trata de uma atividade em expansão, que gera emprego e renda para todos os que compõem a cadeia produtiva da reciclagem.

Contudo, foi somente a partir de 2002 que a ocupação de catador de material reciclável foi incluída na Classificação Brasileira de Ocupações (CBO), com base na revisão realizada pelo Ministério do Trabalho e Emprego (MTE), segundo Nozoe, Bianchi e Rondet (2003). Na CBO, o número é 5192-05 e sua ocupação é denominada como catador de material reciclável, possuindo a seguinte descrição sumária: "Catam, selecionam e vendem materiais recicláveis como papel, papelão e vidro, bem como materiais ferrosos e não ferrosos e outros materiais reaproveitáveis".

De acordo com informações coletadas no site do CBO, a profissão é de livre acesso, sem exigência de escolaridade ou formação profissional, e as atividades são exercidas a céu aberto, em horários variados, ficando os trabalhadores expostos às variações climáticas, aos acidentes na manipulação de materiais, acidentes de trânsito e à violência urbana.

Em 23 de dezembro de 2010, através do Decreto $\mathrm{n}^{\circ}$ 7.405, foi instituído o Programa Pró-Catador, que, em seu artigo $1^{\circ}$, define os catadores: “[...] consideram-se catadores de materiais reutilizáveis e recicláveis as pessoas físicas de baixa renda que se dedicam às atividades de coleta, triagem, beneficiamento, processamento, transformação e comercialização de materiais reutilizáveis e recicláveis". 
Acrescente-se a isso a Política Nacional de Resíduos Sólidos (PNRS), Decreto-Lei $\mathrm{n}^{\mathrm{o}}$ 10.305, de 2 de agosto de 2010, em seu artigo $7^{\circ}$, inciso XII, que prevê a inserção da participação efetiva dos catadores nas ações de responsabilidade compartilhada:

Art. $7^{\circ}$ São objetivos da Política Nacional de Resíduos Sólidos: [...] XII - integração dos catadores de materiais reutilizáveis e recicláveis nas ações que envolvam a responsabilidade compartilhada pelo ciclo de vida dos produtos.

Esses instrumentos jurídicos acabaram por fortalecer a organização dos catadores e difundiram-na como alternativa social e econômica. A PNRS, em seu artigo 22, parágrafo segundo, orienta ao responsável pelos serviços públicos de limpeza urbana e manejo de resíduos que priorizem a contratação de organizações produtivas de catadores de materiais recicláveis.

\section{O conhecimento, o trabalho coletivo em rede e sua relação social com os catadores de materiais recicláveis}

Faz-se necessário, mesmo que de modo breve, explanar o que seja o conhecimento. A etimologia do termo vem do latim cognoscere, que significa "vir a saber". É o ato ou efeito de conhecer. A raiz da palavra - conhecimento - referese a nome ou gnomen. Ou seja, "[...] conhecer, na origem, significava dar nome às coisas. Trata-se, portanto, de uma operação intelectual que nomeia conceitos construídos a partir da compreensão de características identitárias na definição de várias coisas particulares." (CAMARGO, 2013, p. 41).

Desse modo, tradicionalmente, somente poderia existir conhecimento se o logos (palavra, discurso, mente) fosse incorporado à linguagem verbal por meio de sua compreensão num conceito.

De acordo com Piaget (2007, p. 1),

[...] o conhecimento não pode ser concebido como algo predeterminado nem nas estruturas internas do sujeito, porquanto estas resultam de uma construção efetiva e contínua, nem as características preexistentes do objeto, uma vez que elas só são conhecidas graças à mediação necessária dessas estruturas, e que estas, ao enquadrá-las, enriquecem-nas (quando mais não seja para situá-las no conjunto dos possíveis). 
Nesse sentido, é importante frisar que o conhecimento não se dá tão somente pelas estruturas internas (inatas ao sujeito) nem, tampouco, somente pelas experiências empiristas, sensoriais e do ambiente (externas ao sujeito). O conhecimento se dá a partir de construções historicamente situadas, a partir das relações e interações que são estabelecidas entre os sujeitos, os objetos, a natureza e o social.

O conhecimento deve ser compreendido não de forma isolada, mas sim a partir de um contexto de conteúdos e ações pedagógicas - aqui entendidas enquanto práticas sociais de escolarização formal exercida pela escola, que se encontra para satisfazer o direito e o desejo de apreender os conhecimentos construídos e acumulados pela humanidade ao longo da história.

Cyrino e Penha (1992) apontam vários tipos de conhecimento. Dentre eles, o conhecimento da vida, que se constitui como conhecimento adquirido pelo homem a partir de experiências, vivências e observações do mundo. É uma forma de senso comum. Caracteriza-se por conhecimentos empíricos acumulados ao longo da vida e transmitidos de geração em geração. Assim é que a ciência e o senso comum, midiatizados pela ação dos sujeitos, vão se articulando, transformando-se e adquirindo a forma e o conteúdo que aquele momento de construção exige. Nessa relação, percebe-se a importância tanto do conhecimento, enquanto saber sistematizado, quanto do senso comum, enquanto saber não sistematizado, mas capaz de dinamizar a ação e transformá-la.

Nesse caminho, deduz-se que o saber, o conhecimento, a ação e o pensamento constituem, respectivamente, o que se chama de práxis, ou seja, a percepção de que toda teoria e prática devem ser vistas como partes necessárias e não antagônicas de um todo que perfaz o conhecimento que alimenta a ação e que a transforma.

Acompanhando o pensamento de Kosik (1976), ao afirmar que o fenômeno (momento empírico do senso comum) não é a essência, mas está contido nela, entender-se-á que o senso comum é parte do todo e, como tal, deve ser compreendido como o ponto de partida para a construção do conhecimento pelos sujeitos que aprendem. Seguindo essa mesma linha de raciocínio, em que teoria e prática são partes de um mesmo bloco, sem perderem sua especificidade, entendese que a educação tem sido a mola propulsora de uma prática social que não é neutra, pois atende a objetivos e interesses próprios e determinados historicamente que beneficiam a uma ou a outra classe conforme compreendem a serviço de quem estão.

Assim também o trabalho coletivo e a educação são frutos da cultura humana, da prática social, da sociabilidade e do relacionamento humano. Por isso, o trabalho coletivo pode oferecer elementos importantes para a educação, se considerada a cooperação como base da sociabilidade. É o que pensa Maturana (1997), ao afirmar que somente são sociais as relações que se baseiam na convivência 
humana, no respeito e na aceitação recíproca ao outro. A cooperação, portanto, está na raiz da sociabilidade, conforme Maturana (1997, p. 97):

A convivência social se funda e se constitui na aceitação, no respeito e na confiança mútuos, criando assim um mundo comum. E, nessa aceitação, nesse respeito e nessa confiança mútuos é que se constitui a liberdade social. Isto é assim porque a constituição biológica humana é a de um ser que vive no cooperar e no compartir, de modo que a perda da convivência social traz consigo a enfermidade e o sofrimento.

É com esse entendimento que se acredita que, por meio do trabalho coletivo ${ }^{1}$ nas redes organizacionais, enquanto práticas sociais pautadas em princípios de gestão democrática e comprometidas com a emancipação humana, os catadores de materiais recicláveis possam não somente minorar o quadro de pobreza de sua existência material, mas também voltar ou iniciar um processo de escolarização formal que os instrumentalize para a compreensão das diferentes e contraditórias formas de relações humanas e de trabalho.

Historicamente, a atividade de catador de material reciclável é realizada a partir de relações informais e de alta precariedade laboral. Muitos deles exercem a atividade já há um longo tempo, em alguns casos, desde a infância, com uma rotina diária bastante desgastante. Há os que trabalham sozinhos ou em família, e aqueles que se agrupam em associações, cooperativas ou redes no intuito de somar forças por meio do trabalho coletivo (SILVA; GOES; ALVAREZ, 2013).

Nesse contexto, rememore-se que o termo "rede" é derivado do latim "retis" ou teia e designa um conjunto entrelaçado de fios, cordas, arames etc, fixado por malhas e nós, constituindo um tecido aberto com aberturas regulares. Assim, é importante destacar as conclusões de Freire (1998) e Powell, Koput e Smith-Doerr (1996) sobre o estudo das redes organizacionais. Para o primeiro, no funcionamento das redes, não se perde a autonomia de cada organização, que é coordenada por um órgão central, que busca otimizar o desempenho do conjunto. No entendimento do segundo autor, as organizações buscam ganhar legitimidade junto ao seu ambiente institucional no momento de se estruturarem em rede. Portanto, as redes organizacionais permitem alcançar maior flexibilidade, compartilhar recursos e enfrentar novos ambientes, dividindo-se os riscos (SOTO, 2010).

Para superar o isolamento (trabalho individual) é que as redes de catadores contemplam o trabalho coletivo, a cultura colaborativa e de equipe, entendendo

\footnotetext{
${ }^{1}$ Conjunto de pessoas unidas por um objetivo comum e/ou independentes, que desenvolvem o seu processo grupal (BORBA; SEMINOTTI, 2009).
} 
ser esse o caminho mais adequado e promissor para se alcançar um bom desempenho e, assim, construir as condições necessárias para a melhoria da qualidade de vida desses atores sociais.

Nesse sentido, a atuação em rede busca fortalecer os laços e as experiências dos catadores na superação das dificuldades presentes ao longo do processo de coleta de materiais recicláveis.

\section{Metodologia}

A seguir, apresenta-se a descrição do método empregado para coleta de dados, bem como a descrição geral da Rede de Catadores de Resíduos Sólidos Recicláveis do Estado do Ceará, cujos gestores e trabalhadores (catadores) participaram do estudo. O trabalho de campo foi desenvolvido no período de fevereiro a novembro de 2014.

\section{Rede de Catadores de Resíduos Sólidos Recicláveis do Estado do Ceará}

A Rede de Catadores de Resíduos Sólidos Recicláveis do Estado do Ceará surgiu como uma estratégia de construção de um espaço coletivo, democrático e participativo, configurando um consórcio estabelecido entre 19 (dezenove) grupos informais e associações de catadores. Foi criada como associação civil de direito privado, em 3 de abril de 2007, tendo como objetivo desenvolver ações conjuntas entre as associações, cooperativas e grupos de catadores de Fortaleza e da Região Metropolitana (RMF). A Figura 1 mostra a representação geográfica dos 19 (dezenove) municípios que integram a RMF, quais sejam: Fortaleza, Caucaia, Maranguape, Pacatuba, Aquiraz, Maracanaú, Eusébio, Itaitinga, Guaiuba, Chorozinho, Pacajus, Horizonte, São Gonzalo do Amarante, Pindoretama, Cascavel, Paracuru, Paraípaba, Trairi e São Luiz do Curu. Os últimos quatro municípios foram incluídos no ano de 2014. 
Figura 1 Região Metropolitana de Fortaleza

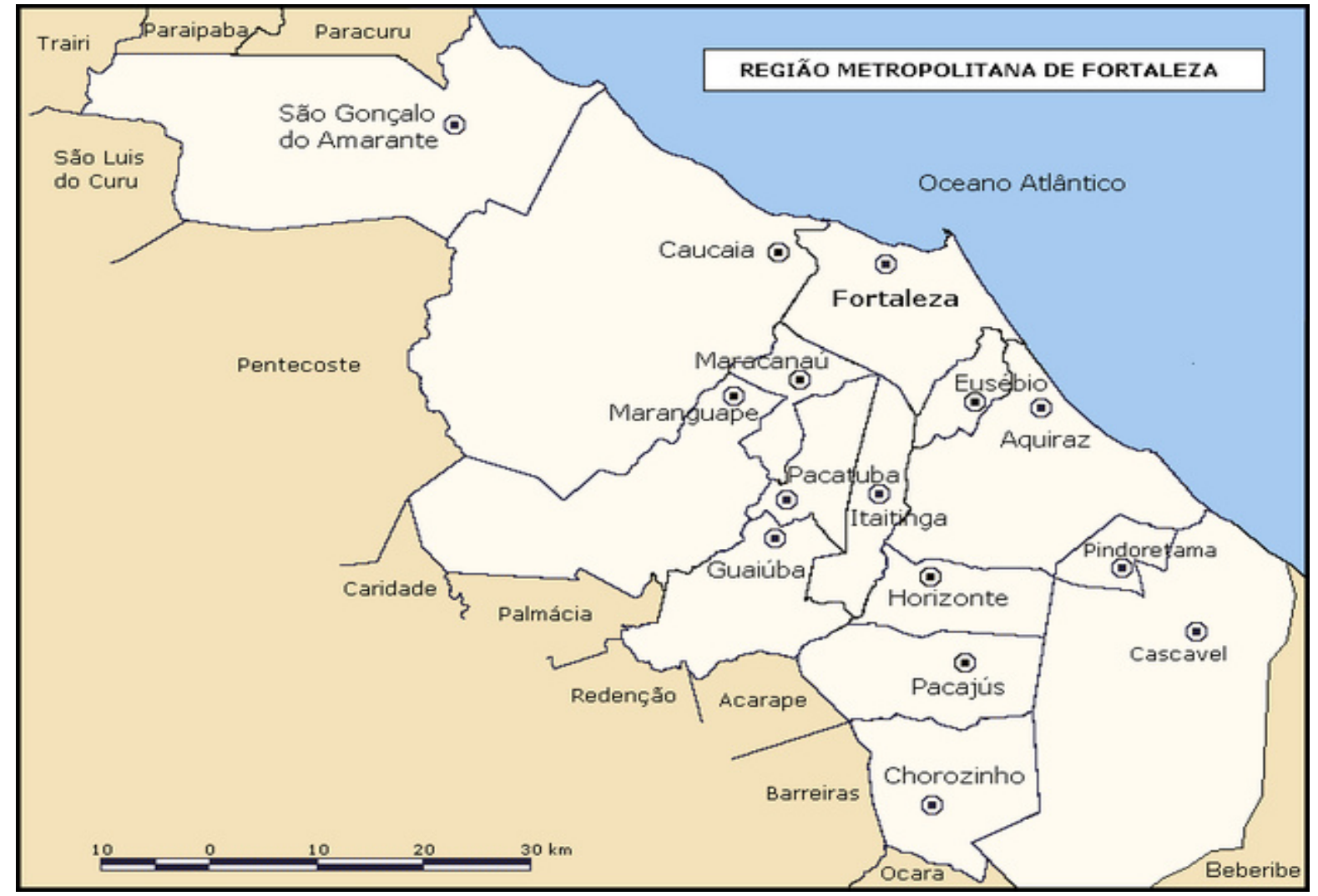

Fonte: Google Maps (2015).

A RMF concentra 64,1\% do Produto Interno Bruto (PIB) do estado do Ceará, que, em 2013, foi de R \$ 42.010.111 (IBGE, 2014), com 3.818.380 habitantes em 2014, sendo a oitava maior região metropolitana do Brasil. Esses dados corroboram a importância da rede de catadores nos âmbitos social, econômico e ambiental para a RMF ou Grande Fortaleza.

A Rede de Catadores de Resíduos Sólidos Recicláveis realiza a coleta seletiva, a reciclagem de embalagens pós-consumo e a coleta do OGR (óleo de gorduras residuais), facilitando sua comercialização em rede para a usina de biodiesel da Petrobrás. A coleta e a reciclagem estão previstas na Lei n ${ }^{\circ} 12.305 / 10$, PNRS, que responsabiliza os geradores de lixo e os obriga a mitigarem os impactos através da logística reversa.

A rede atualmente congrega 25 (vinte e cinco) associações e 3 (três) cooperativas, tendo 800 (oitocentos) catadores cadastrados. Oitenta por cento (80\%) estão dispersos nas ruas e lixões e não são associados de nenhuma cooperativa ou associação. Os demais catadores realizam atividades de gestão e de seleção de material reciclado no interior do prédio da Rede.

Hoje, a diretoria e os membros tentam se articular politicamente para conseguir recursos e melhorar as condições de trabalho dos catadores. Nesse sentido, após 
muitas discussões e negociações, em 6 de dezembro de 2012, foi lançado o Plano Municipal de Gestão Integrada de Resíduos Sólidos (PMGIRS), que é um desdobramento da PNRS. A organização (rede), defendida em lei, recebe recursos específicos.

\section{Participantes}

Participaram do estudo cinco catadores de material reciclável, todos associados à Rede, quatro do sexo masculino e um do sexo feminino. Os trabalhadores foram indicados pela própria Rede, segundo a disponibilidade de tempo que cada um tinha para participar das entrevistas, desde que tivessem pelo menos seis meses de trabalho com a catação de lixo e estivessem formalmente cadastrados na Rede. Dentre os cinco participantes, a média de catação é de cinco anos.

Todos os participantes são casados, com uma média de três filhos por família. Nenhum dos cinco sujeitos pesquisados recebe salário com valor definido mensalmente. A remuneração média recebida por cada um varia de $\mathrm{R} \$ 25,00$ a $\mathrm{R} \$$ 40,00, com exceção do período da Copa do Mundo de futebol (2014), no qual os catadores foram beneficiados individualmente com diárias que variaram de $\mathrm{R} \$$ 80,00 a $\mathrm{R} \$ 100,00$, fazendo com que os catadores ganhassem, ao final do contrato de dois meses com a Prefeitura Municipal de Fortaleza, entre $\mathrm{R} \$ 1.200,00$ e $\mathrm{R} \$$ 2.600,00 por 8 (oito) horas ou 4 (quatro) horas trabalhadas por escala. Dois catadores são analfabetos, dois têm o ensino fundamental incompleto (até a $4^{\mathrm{a}}$ série), e um tem o ensino médio incompleto. O trabalhador mais jovem tinha, à época, 42 (quarenta e dois) anos; o mais velho, 56 (cinquenta e seis) anos. Somente um dos trabalhadores já teve experiência formal, com carteira assinada, e, por fim, todos residem em imóvel alugado.

\section{Instrumento de coleta de dados}

Para realização das entrevistas individuais semiestruturadas, foi elaborado e desenvolvido um roteiro composto por três blocos. No primeiro bloco, buscou-se a identificação pessoal dos trabalhadores (ano de nascimento, escolaridade, estado civil e número de filhos). O segundo bloco da entrevista tratou das condições econômicas dos catadores de material reciclável e o terceiro bloco versava sobre o seu entendimento acerca das temáticas: conhecimento, trabalho coletivo e redes organizacionais. 
O acesso ao ambiente da Rede de Catadores de Resíduos Sólidos Recicláveis do Estado do Ceará se deu mediante contato prévio com a presidente. Inicialmente, foram realizadas três visitas para a realização das entrevistas e uma para observação livre do ambiente de trabalho dos catadores. A observação livre foi realizada nos locais de recolhimento de lixo e nos depósitos privados que compram seus materiais coletados.

As três visitas subsequentes permitiram realizar as cinco entrevistas individuais semiestruturadas, que se constituíram na principal fonte de dados do estudo. Cada entrevista com os trabalhadores indicados pela própria rede e que atendiam aos critérios estabelecidos durou aproximadamente trinta minutos e teve como local a sede da organização.

Para esses trabalhadores, foram feitas a apresentação do pesquisador e as informações do estudo a ser realizado. Depois de obtida a concordância dos trabalhadores em participarem de todo o processo, houve a gravação, em áudio, das entrevistas, a fim de dirimir eventuais dúvidas na análise dos conteúdos. As entrevistas foram mantidas sem modificações ou correções.

\section{Análise dos dados}

Os dados foram tratados mediante análise de conteúdo do tipo categoria temática (BARDIN, 1997); a análise foi realizada em três etapas cronológicas: pré-análise, exploração do material e interpretação. As categorias temáticas empíricas construídas foram três: 1) conhecimento; 2) trabalho coletivo e 3) rede organizacional.

No Quadro 1, a seguir, apresentam-se as categorias, suas definições e temas. 
Quadro 1 Categorias temáticas

\begin{tabular}{|l|l|l|}
\hline \multicolumn{1}{|c|}{ Categoria temática } & \multicolumn{1}{|c|}{ Definição } & \multicolumn{1}{c|}{ Tema } \\
\hline Conhecimento & $\begin{array}{l}\text { É o conhecimento } \\
\text { formal legal. Grau de } \\
\text { escolarização. }\end{array}$ & Formação. Qualificação. \\
\hline Trabalho Coletivo & $\begin{array}{l}\text { Conjunto de pessoas } \\
\text { unidas por um objetivo } \\
\text { comum. }\end{array}$ & $\begin{array}{l}\text { Trabalho em equipe. } \\
\text { Cooperação. }\end{array}$ \\
\hline Rede Organizacional & $\begin{array}{l}\text { Atuar em rede significa } \\
\text { fortalecer os laços e as } \\
\text { experiências dos } \\
\text { catadores na superação } \\
\text { de dificuldades. }\end{array}$ & $\begin{array}{l}\text { Gestão democrática. } \\
\text { Compartilhar recursos. }\end{array}$ \\
\hline
\end{tabular}

Fonte: Elaboração própria.

Todas as categorias temáticas foram estabelecidas a partir do referencial teórico e procuram sintetizar o assunto identificado pela análise de conteúdo.

\section{Resultados}

As verbalizações apresentadas na sequência atendem as categorizações temáticas definidas no estudo, acompanhadas das respectivas discussões.

Categoria 1 - Conhecimento
Pra catar lixo não é necessário estudar (Sujeito 1)
Estudei muito pouco [...] sei assinar o nome (Sujeito 5)
[...] só foram nos dois primeiros anos à escola, então são, na sua maioria, analfabetos ou semianalfabetos. Inclusive a maioria mal sabem assinar (Sujeito 4).

Pode-se verificar que o conhecimento formal praticamente inexiste na vida desses sujeitos, sendo predominante o conhecimento advindo da vida prática (Cyrino e Penha, 1992), ou seja, o do senso comum, o que não deixa de ser reconhecido como um tipo de saber: o saber popular ou não sistematizado. Essa escolarização é insuficiente para que esse trabalhador seja absorvido pelo mercado formal, enquanto força de trabalho qualificada. De acordo com o Sujeito 4, os catadores 
de resíduos participam de formação profissional para a realização do seu trabalho; entre os conteúdos destacam-se associativismo, fortalecimento da rede, liderança, beneficiamento do material, entre outros.

\section{Categoria 2 - Trabalho Coletivo}

Trabalhar coletivamente é coletar nas casas (Sujeito 2).

Trabalho coletivo é quando nós se reúne no próprio depósito para beber em grupo (Sujeito 1).

Através da triagem do material do BNB-Passaré (através do Decreto 5.940), onde fizemos um trabalho em rede durante mais ou menos dois anos, para formar um fundo para manter a rede e trocar experiência de triagem, comercialização e administração de associação (Sujeito 4).

As respostas acima referidas demonstram que os entrevistados, por realizarem um trabalho individual em relação direta com os depósitos privados que compram seus materiais coletados, e por não pertencerem a nenhuma cooperativa ou associação, não vivenciam trabalhos coletivos, tampouco desenvolvem algum tipo de reflexão sobre o conceito e a importância desse modo de trabalho. As respostas são curtas e expressas a partir do senso comum. As entrevistas demonstram que os respondentes (exceto o Sujeito 4) não se aproximam do conceito de trabalho coletivo de Borba e Seminotti (2009).

\section{Categoria 3 - Redes Organizacionais}

Algum tipo de depósito que trabalha com material reciclável (Sujeito 5).

Uma associação que coleta material (Sujeito 2).

Aqui no Ceará, as condições são mínimas, por isso não temos como bancar impostos e tributos de quanto cooperativas, então é mais viável o associativismo, mas, para a comercialização em rede, foi preciso formarmos cooperativas regionais em rede (de segundo grau) para a emissão de notas fiscais. Temos 3: Região do Cariri, Vale do Jaguaribe e da de Fortaleza e Região Metropolitana. São três cooperativas dentro da rede estadual (Sujeito 4).

Vale mencionar que somente um dos sujeitos de pesquisa (o de número 3), de forma incipiente, fez alusão à questão da gestão democrática: "Um grupo unido e o que faz divide". O isolamento da atividade de catação de lixo relega o trabalhador a uma posição desfavorável na cadeia produtiva, isto é, gera pouco valor agregado.

Para alterar esse quadro, a formação de uma rede possibilita construir a sustentabilidade do trabalhador e do negócio. Ao ser criada, a Rede de Catadores 
de Resíduos Sólidos Recicláveis do Estado do Ceará permitiu a implantação de elos que aproximaram a cadeia produtiva, eliminou intermediários e gerou valor agregado ao produto comercializado (lixo).

O ingresso dos trabalhadores na rede se dá, de acordo com as entrevistas, pelo desemprego, independência, remuneração, e há aqueles que sempre trabalharam com lixo, conforme verbalizações abaixo transcritas:

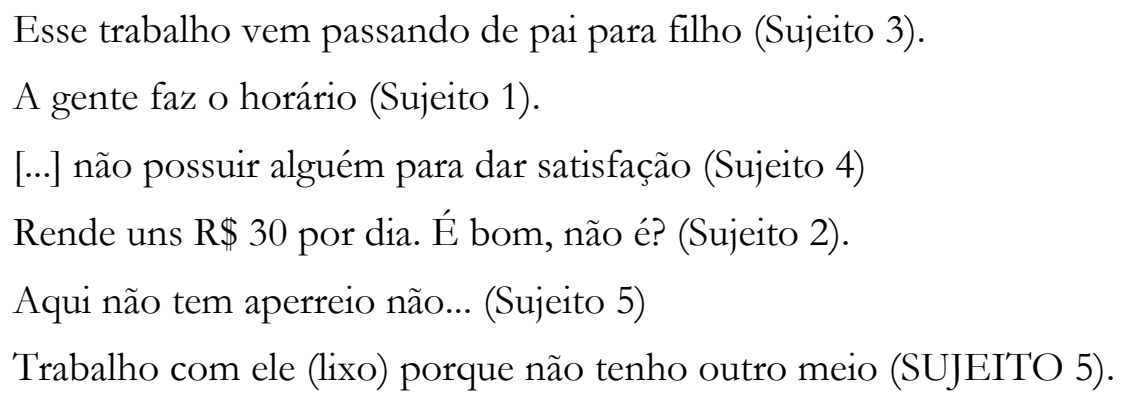

Nas entrevistas, também foi identificado que os catadores trabalham com a ajuda dos filhos, esposas ou maridos. Esse procedimento aumenta a renda familiar e proporciona um volume maior de material para reciclagem.

A formação da rede aumentou a capacidade de articulação com outras organizações e fortaleceu o grupo na busca dos seus objetivos, conforme relato do sujeito 4:

[...] fizemos um trabalho durante a Copa do Mundo que rendeu dois contratos. A renda do material coletado nesses dois contratos foi concordado em 20\% pra Rede Regional, e o restante distribuído igualmente para as associações que enviaram catadores para o trabalho.

Portanto, a atuação em rede valoriza e reconhece a categoria, traz garantias na política municipal de resíduos sólidos, dá publicidade ao trabalho, sensibiliza a comunidade, amplia a participação e a gestão democrática, propicia aos grupos de catadores a troca de experiências, o companheirismo, a solidariedade, entre outros.

Os resultados verificados permitem ampliar a compreensão sobre o contexto do conhecimento e sua influência na escolha do trabalho coletivo em forma de rede. Para ampliar os resultados alcançados, sugere-se o desenvolvimento de um número maior de entrevistas coletivas semiestruturadas ou a formação de grupos focais. 


\section{Considerações finais}

A realidade dos catadores de materiais recicláveis (lixo) é decorrente de um crescimento urbano desordenado, da falta de oportunidades em relação ao mercado de trabalho, do elevado grau de exclusão social a que estão submetidos, dentre outros. Os catadores vivem nessa condição por necessidade de sobrevivência, e não por reconhecerem na ocupação uma atividade que contribui para a sustentabilidade do meio ambiente, por exemplo.

Ademais, os trabalhadores (catadores) encontram na catação a possibilidade de garantir a sobrevivência, mesmo que, ao executar essa atividade, não possuam qualquer garantia trabalhista; no entanto, a partir dela, sentem-se novamente incluídos. Medeiros e Macedo (2007) denominam esta de 'inclusão perversa', pois a lucratividade dessa atividade fica com terceirizados e com pessoas de diferentes segmentos da cadeia produtiva, o que conduz a uma nova exclusão dos catadores.

A premissa inicial deste estudo era a de que se os catadores de materiais recicláveis possuíssem conhecimento formal sobre as possibilidades de escolherem o trabalho coletivo colaborativo em rede como o mais efetivo. Os resultados da pesquisa indicam que os catadores quase não possuem escolaridade formal, ou seja, em sua maioria, são analfabetos.

No cenário da ocupação de catador, "[...] o saber é exercitado no coletivo, no qual se conhece a realidade [...]", segundo Bertoldi (2009, p. 109). Tal afirmativa corrobora com os resultados obtidos nesta pesquisa, isto é, poucos sabem ler e escrever e, em suas relações, constroem sua condição de sujeito a partir da vivência ou prática. Entretanto, com a baixa escolaridade e a falta de qualificação, as oportunidades de emprego ficam limitadas, o desemprego se fortalece e a frustração ganha nova dimensão.

Todavia, para que a educação reverbere em uma tomada de consciência deste segmento para a importância de resolver seus problemas com a ajuda dos outros, ou seja, a partir de um coletivo, faz-se necessário que a escola seja de fato includente e que contemple, em sua proposta pedagógica, conteúdos relativos às temáticas de organização social, inclusive as que se referem ao sistema em rede.

As diversas formas de conhecimento podem constituir um trabalho coletivo em que a cooperação pode ser compreendida como um meio de construção de aprendizagens cotidianas e contínuas, isto é, das práticas sociais de convivência humana.

Finalizando, é possível compreender que, desde a era mais primitiva, os seres humanos foram capazes de encontrar soluções e novos significados por meio do trabalho coletivo. Portanto, o aprendizado, as trocas sociais, a cooperação e o trabalho coletivo fazem parte dessas relações cotidianas na Rede de Catadores de Resíduos Sólidos do Estado do Ceará. 


\section{Referências}

ABREU, M. de F. Do lixo à cidadania: estratégias para a ação. Brasília/DF: CEF, 2001.

BARDIN, L. Análise de conteúdo. Lisboa: Edições 70, 1997.

BORBA, P. M.; SEMINOTTI, N. O trabalho coletivo nas organizações como estratégia de produção de saúde. Anais... IV Mostra de Pesquisa e PósGraduação, PUCRS, 2009.

BORTOLDI, M. A. Catadores de materiais recicláveis: a construção de novos sujeitos políticos. Revista Katálysis, Florianópolis, v. 12. n. 1, jan./jun., 2009. BRASIL. Decreto Lei no 10.305/2010. Política Nacional de Resíduos Sólidos. Disponível em: <http://www.planalto.gov.br>. Acesso em: 29 jan. 2015.

. Decreto Lei n ${ }^{\circ}$ 12.305/2010. Política Nacional de Resíduos Sólidos. Disponível em: <http://www.planalto.gov.br>. Acesso em: 29 de jan. 2015.

. Decreto Lei no 7.405/2010. Programa Pró-Catador. Disponível em: <http://planalto.gov.br>. Acesso em: 29 de jan. 2015.

CALDERONI, S. Os bilhões perdidos no lixo. São Paulo: Humanitas Editora/FFLCH-USP, 2003.

CAMARGO, M. H. Arte: uma questão epistemológica. Revista Travessias, Ed. $\mathrm{XV}$, v. 7, n. 2, 2013.

CLASSIFICAÇÃO BRASILEIRA DE OCUPAÇÕES. Brasília/DF: Ministério do Trabalho e Emprego. Disponível em: <http://www.mtecbo.gov.br>. Acesso em: 28 jan. 2015.

CYRINO, H.; PENHA, C. Filosofia hoje. Campinas: Papirus, 1992.

FREIRE, A. Estratégia. Portugal: Editora Berbo, 1998.

GONÇALVES, R. C. M. A voz dos catadores de lixo em sua luta pela sobrevivência. Dissertação de Mestrado. Fortaleza: UECE, 2005.

IBGE. Instituto Brasileiro de Geografia e Estatística. Produto Interno Bruto. Disponível em: <http://www.ibge.gov.br>. Acesso em: 4 de jan. 2014. 
KOSIC, K. Dialética do concreto. Rio de Janeiro: Paz e Terra, 1976.

LOCATELLI, A. F.; SANCHEZ, R. S. da S.; ALMEIDA, F. Q. A. de. Redução, reutilização e reciclagem de resíduos em unidade de alimentação e nutrição. Revista Simbiologias, v. 1, n. 2, nov., 2008.

MATURANA, H. Emoções e linguagem na educação e na política. Belo Horizonte: UFMG, 1997.

MEDEIROS, L. F. R. de.; MACEDO, K. B. Profissão: catador de material reciclável, entre o viver e o sobreviver. Revista Brasileira de Gestão e Desenvolvimento Regional, v. 3, n. 2, mai./ago., 2007.

- Catador de material reciclável: uma profissão para além da sobrevivência? Revista Psicologia e Sociedade, 18(2), mai./ago., 2006.

NOZOE, N. H.; BIANCHI, A. M.; RONDET, A. C. A. A nova classificação brasileira de ocupações: anotações de uma pesquisa empírica. Revista São Paulo em Perspectiva, v. 17, n. 3-4, jul./dez., 2003.

PIAGET, J. Epistemologia genética. São Paulo: Martins Fontes, 2007.

PINHEL, J. R. (Org.). Do lixo a cidadania: guia para a formação de cooperativas de catadores de materiais recicláveis. Instituto de Projetos e Pesquisas SócioAmbientais. Rio de Janeiro: Petrópolis, 2013.

POWELL, W.; KOPUT, K. e SMITH-DOERR, L. Interorganization collaboration and the locus innovation: networks of learning in biotechnology. Journal of Administrative Science Quartely, v. 41, 1996.

QUIRINO, L. B. et al. Reciclagem artesanal de resíduos vítreos: proposta de sustentabilidade para um grupo de catadores. Anais... IX Congresso Brasileiro de Pesquisa e Desenvolvimento em Design. Universidade Anhenguera Murumbi/SP, 2010.

SILVA, S. P.; GOES, F. L.; ALVAREZ, A. R. Situação social das catadoras e catadores de material reciclável e reutilizável. Brasília/DF: IPEA, 2013.

SOTO, M. M. T. Análise e formação de redes cooperativas de catadores de materiais recicláveis no âmbito da economia solidária: cadeia produtiva de reciclagem. Tese de Doutorado. Rio de Janeiro: UFRJ/COPPE, 2010. 
ZANETTI, I.; GENTIL, V.; TORRES, H. Cooperativas e associações de catadores de resíduos sólidos no DF: questões socioeconômicas, ambientais e sustentabilidade. Anais... Encontro da ANPPAS, Brasília/DF: UNB, 2008.

Endereço para correspondência:

Roberto Tadeu Ramos Morais - posgrad@faccat.br Av. Oscar Martins Rangel, 4500

95600-000 Taquara/RS, Brasil

Newton José Cavalcante Gonçalves - posgrad@faccat.br Av. Oscar Martins Rangel, 4500

95600-000 Taquara/RS, Brasil 